\title{
A Contrastive Study of Realization Patterns of Request Strategies of Ilami-Kurdish and Persian Speakers based on Age and Education
}

\author{
Parisa Valizadeh \\ English Department, Ilam Branch, Islamic Azad University, Ilam, Iran \\ E-mail: pa_valizadeh@yahoo.com \\ Habib Gowhary (Corresponding author) \\ English Department, Ilam Branch, Islamic Azad University, Ilam, Iran \\ E-mail: h_gowhary@yahoo.com \\ Akbar Azizifar \\ English Department, Ilam Branch, Islamic Azad University, Ilam, Iran \\ E-mail: Akb1354@yahoo.com
}

Received: 24-02- 2015

Accepted: 11-05- 2015

Published: 01-09- 2015

doi:10.7575/aiac.ijalel.v.4n.5p.255 URL: http://dx.doi.org/10.7575/aiac.ijalel.v.4n.5p.255

\begin{abstract}
This paper aimed at investigating speech act of 'request realization patterns' in Ilami Kurdish and Persian languages. It attempts to systematize the various strategies used for the purpose of request from the pragmatic point of view. We focus on the impact of gender, age and language as well as degree of education on the choice of forms of request in Ilami kurdi and Persian. It is intended to find the most frequently used strategies in different social groups based on their language, age and level of education. To achieve this goal, a descriptive approach was adopted by employing a researcher-made questionnaire to collect the data from a population of bilingual and monolingual subjects in Ilam, Iran. A remarkable finding was the meaningful relationship among age and level of education in request strategies used by Ilami Kurdish and Persian speakers. As for the kind of language, it was found that "Supportive moves" and "Internal modifier" were the most frequently used strategies among Kurdish subjects respectively and "Supportive moves" and "Internal modifier" was the most popular employed strategies among Persian subjects respectively. As for age, it was found that out of the 69 collected request responses, "Internal modifier" and "Supportive moves " were the most frequently used strategies among under 26 years subjects respectively and "Internal modifier" and "Alerters" were the most popular employed strategies among above 26 years subjects respectively. Finally, regarding the level of education, it was found that "Internal modifier" and out of the 54 collected request responses, "Internal modifier" was the most frequently used strategies among B.A and M.A subjects respectively. The same table shows that out of 47 collected request responses "Internal modifier" and "Supportive moves" was the most popular employed strategies among PHD subjects respectively.
\end{abstract}

Keywords: request, speech act, Kurdish- Persian, realization

\section{Introduction}

The way we create speech acts depends on the variety of interpersonal and individual variables such as degree of confidence, age differences, hierarchy, form of perception and social interaction, personal characteristic, etc. Interpersonal (interaction of individual consciousness with the group consciousness and wider environment) and individual or intrapersonal variables (linguistic and social consciousness of individuals) determine the choice of linguistic and extra linguistic elements as well as politeness strategies that depend on the person and his/her own culture (Diaz- perez, 2003). For a long time, linguists were only concerned with the form and structure of language apart from its social context and social factors influencing the language. This was obviously the case with structural linguistics. In recent years, the relevance of pragmatics has become increasingly clear to applied linguists.

Through the scope of pragmatics is far from easy to define, the variety of research interests and developments in the field share one basic concern, the need to account for the rules that govern the use of language in context (Levinson, 1983). Language is tool to make possible the communications among people. Speech acts are statement we use to transfer our intensions. Cross-cultural speech act realization patterns (CCSARP) project initiated in 1982 was an attempt to analyze speech acts, (in this case requests) across a range of languages and cultures aiming at investigating the existence of any possible pragmatic universals and their characteristics. Olshtain $(1989$, p.171) point out that the CCSRP data showed surprising similarities in IFID, (ILLOCUTIONARY Force Indicating Devise) and expression of responsibility preferences. 
Successful communication entails knowledge's of grammar and text organization as well as pragmatic target language. Pragmatic competence is specifically defined by Koike (1989) as "the speaker's knowledge and use of rules of appropriateness and politeness which dictate the way the speaker will understand and formulate speech acts" (p.279).

In recent years, the relevance of pragmatics has become increasingly clear to applied linguists. Through the scope of pragmatics is far from easy to define, the variety of research interests and developments in the field share one basic concern. The need to account for the rules that govern the use of language in context (Levinson 1983). One of the basic challenges for research in pragmatics is the issue of universality; to what extent is it possible to determine the degree to which the rules that govern the use of language in context vary from culture to culture and from language to language? Answers to this question have to be sought cross- cultural research in pragmatics. For applied linguistics, especially for those concerned with communicative language learning and teaching, cross- cultural research in pragmatics is essential in coping with the applied aspect of the issue of universality. To what extent is it possible to specify the particular pragmatic rules of use for a given language, rules which second language learners will have to acquire in order to attain successful communication in the target language?

Studies have demonstrated that there are cross-cultural differences between two different speech communities in relation to the type of request and level of directness of request realization (Blum-kulka and Olshtain, 1984, Blum-kulka and House, 1989, Eslami- Rasekh, 1993, Wierzbicka, 1991). Most of these studies have dealt with request strategies based on the model proposed by Brown and Levinson (1987). Few however have focused on the perception of politeness (Fraser, 1978, Kitao, 1990).

With the goal of investigating cultural differences which exist between Persian and English, several studies have been carried out focusing on the realization of different speech acts in an Iranian context. These include apologies (Afghary 2007) complaints( Eslami- Rasekh, 2004, Salmani-Nodoushan, 2006a) griping (Allami,2006) invitations (SalmaniNodushan, 2006b),requests(Eslami- Rasekh, 1993,Jalilifar, 2009)and refusals (Moradkhani and Feyzi, 2008). These studies provide readers with a fuller understanding of speech acts in intra and cultural communication. Requests are one of the many speech acts frequently used in human interaction, Because of the large degree of imposition that making a request places upon ones interlocutors, numerous studies have examined its function in different culture. Fukushima (2000) for example conducted a cross cultural study of polite request strategies in British English and Japanese. He showed that British and Japanese undergraduate respondents use different politeness strategies when making requests. He concluded that perceptions of power, social distance and the weight of the imposition influenced politeness strategy choice in the two cultures differently. The purpose of this study is to investigate request strategies of Iranian KurdishPersian and speech acts realization pattern regarding to Age and Education.

Thus the following research questions are addressed in the present study:

1) What are the request strategies used by Iranian Kurdish and Persian languages?

2) What are the difference between the request strategies used by Male and Females?

3) What is the most frequency use request strategy among different level of education?

\section{Methods}

\subsection{Instrument}

The data for this study were collected by means of a questionnaire. The questionnaire consisted of two parts. Part one aimed at eliciting personal information about the participants to make the task of categorization possible .In part two, items were included that asked the participants to choose the request forms they usually use for interaction with their interlocutors in the situations described. The test is composed of 19 situations (request) representing different social contexts (see Appendixes). In order to identify the request strategies used, the researcher used tables to clarify the method used to show the other request strategies employed in each situations and their percentage. In the present study descriptive and inferential statistical techniques have been used to show the meaningfulness the relationship between age and level of education of respondents and use of request strategies.

Each question is given to a panel of expert analysts, and they rate it. They give their opinion about whether the question is essential, useful or irrelevant to measuring the construct under study. Their results are statistically analyzed and the test modified to improve the rational validity. Cronbach Alph is used as an estimate of the reliability and average correlation of a set of items is an accurate estimate of the average correlation of all items that pertain to a certain construct.

\subsection{Procedures}

First of all, a questionnaire was designed base on Blum- Kulka (1984) and some articles. This questionnaire consisted of 19 different situations in request. It was designed in Persian and participants were asked to answer in Persian. The data of this study was collected based on strategies that respondents answered in each situation and each strategy was classified based on models used in western studies about request models. The researcher and his assistants approached the participants in a friendly manner and try to gain their cooperation and assistance in order to fill the questionnaire. They also explained the goals of the research to the participants and assured them that the personal information they provide in the first part of the questionnaire will not be disclosed. In order to emphasize this point, the participants were asked not to write their names on the questionnaire. Therefore, they felt comfortable in responding to the questions. The questionnaire was given to the participants separately and they were asked to answer the questionnaire. 
They were given an oral explanation to elaborate more on what they were asked to do and to explain more about the goals of the research to the participants in order to gain their cooperation and assistance. After the data were gathered, the questionnaires were examined and classified and the six request parameters were counted. After the data were collected, the questionnaires were examined and the incomplete ones were discarded. Then they were classified and codified for the computer analysis (SPSS software). Request strategies have been investigated with questionnaires, focusing on addressee's personal factor (such as language, age and level of education). In order to investigate the social changes in the society and their impact on language, participants from various generations and social strata are required to portray a clear picture of language use as far as request and parameters are concerned. Data analysis techniques including descriptive statistics, frequency, percent and cumulative percent are employed to shed light on actual conditions under which strategies of request is used in Ilami Kurdish and Persian. Because of nature of the study, we have employed mainly descriptive statistics to answer the research questions.

\section{Results}

\subsection{Demographic Statistics}

\subsubsection{Demographic statistics of participants according to age}

The selected participants who answered the questionnaire were 140 people that were under and above 26 years. They were randomly chosen to participate in the study. The following table shows the frequency of the participants according to age.

Table 1. The Frequency and Percentage of Participants According to Age

\begin{tabular}{llll}
\hline & Frequency & Percent & Cumulative Percent \\
\hline under26 years & 69 & 49.3 & 49.3 \\
Above26 years & 71 & 50.7 & 100.0 \\
Total & 140 & 100.0 & \\
\hline
\end{tabular}

As revealed in the above table, 49.3 percent of the participants are under 26 years and the above 26 years are 50.7 percent.

3.1.2 Demographic statistics regarding the language of participants

As stated, the selected respondents to answer the questions were 140 Kurdish and Persian subjects who were randomly chosen to participate in the study. The following table shows the frequency of the respondents in terms of language.

Table 2. The Frequency distribution of respondents in terms of language

\begin{tabular}{llll}
\hline & Frequency & Percent & Cumulative Percent \\
\hline Kurdish & 70 & 50.0 & 50.0 \\
Persian & 70 & 50.0 & 100.0 \\
Total & 140 & 100.0 & \\
\hline
\end{tabular}

As you see in the above table, 50.0 percent of participants are Kurd and other half of them are Persian.

3.1.3 Demographic statistics of participants according to educational degree

Table 3 shows the frequency and percentage of participants according to the level of education.

Table 3. The Frequency and Percentage of Participants According to Educational Degree

\begin{tabular}{llll}
\hline & Frequency & Percent & Cumulative Percent \\
\hline B.A & 39 & 27.9 & 27.9 \\
M.A & 54 & 38.6 & 66.4 \\
PhD & 47 & 33.6 & 100.0 \\
Total & 140 & 100.0 & \\
\hline
\end{tabular}

\subsection{Descriptive statistics}

The distribution of participants' responses to questionnaire is specified in following according to language, gender, age and level of used frequency of the strategies. 
3.2.1 The Frequency distribution of respondents to request questionnaire in terms of language group

Table 4. The Frequency distribution of respondents to request questionnaire in terms of language group

\begin{tabular}{lllll}
\hline language & & Frequency & Percent & Cumulative Percent \\
\hline Kurdish & Direct request & 3 & 4.29 & 4.29 \\
& Conventionally indirect request & 5 & 7.15 & 11.44 \\
& Alerters & 13 & 18.57 & 30.01 \\
& Supportive moves & 27 & 38.57 & 68.58 \\
& Internal modifier & 20 & 28.57 & 97.15 \\
& Hints & 2 & 2.85 & 100.0 \\
& Total & 70 & 100.0 & \\
& Direct request & 2 & 2.86 & 2.86 \\
& Conventionally indirect request & 6 & 8.58 & 11.44 \\
& Alerters & 15 & 21.43 & 32.87 \\
& Supportive moves & 25 & 35.71 & 68.58 \\
& Internal modifier & 18 & 25.71 & 94.29 \\
& Hints & 4 & 5.71 & 100.0 \\
& Total & 70 & 100.0 & \\
\hline
\end{tabular}

As this table reveals, out of the 70 collected request responses, "Supportive moves" and "Internal modifier" were the most frequently used strategies among Kurdish subjects respectively. The same table shows that out of 70 collected request responses "Supportive moves" and "Internal modifier" was the most popular employed strategies among Persian subjects respectively.

The same table shows that out of 70 collected request responses "Supportive moves" and "Internal modifier" was the most popular employed strategies among Persian subjects respectively.

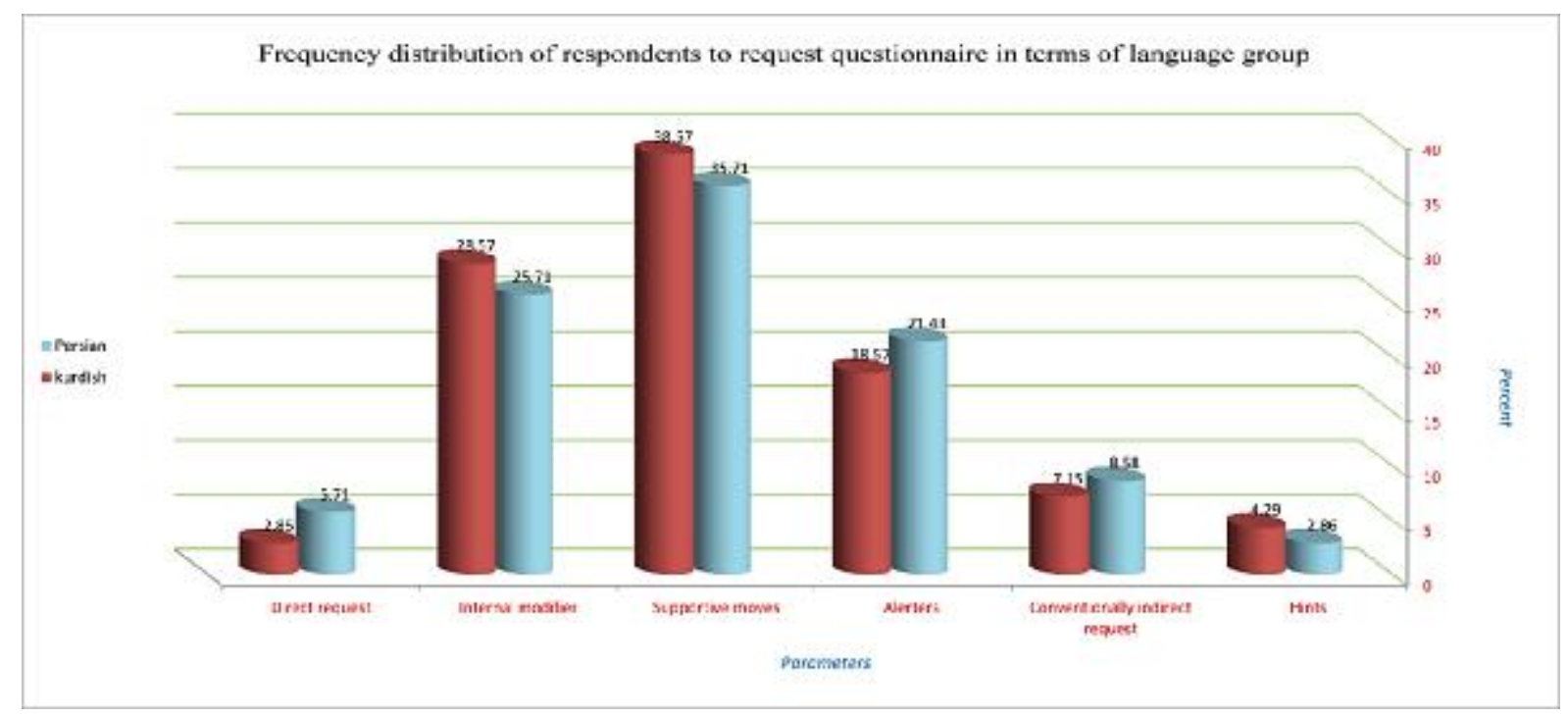

Figure 1. The Frequency distribution of respondents to request questionnaire in terms of language group

3.2.2 The Frequency distribution of respondents to request questionnaire in terms of age group

Table 5. The Frequency distribution of respondents to request questionnaire in terms of age group

\begin{tabular}{cllll}
\hline \multicolumn{1}{c}{ age } & & Frequency & Percent & CumulativePercent \\
\hline under 26 years & Direct request & 4 & 5.80 & 5.80 \\
& Conventionally indirect request & 6 & 8.69 & 14.49 \\
& Alerters & 13 & 18.85 & 33.34 \\
& Supportive moves & 19 & 27.53 & 60.87 \\
& Internal modifier & 26 & 37.69 & 98.56 \\
& Hints & 1 & 1.44 & 100.0 \\
& Total & 69 & 100.0 & \\
above 26 years & Direct request & 5 & 7.04 & 7.04 \\
& Conventionally indirect request & 7 & 9.87 & 16.91 \\
& Alerters & 16 & 22.53 & 39.44 \\
& Supportive moves & 15 & 21.12 & 60.56 \\
& Internal modifier & 26 & 36.63 & 97.19 \\
& Hints & 2 & 2.81 & 100.0 \\
\hline & Total & 71 & 100.0 & \\
\hline
\end{tabular}


As this table reveals, out of the 69 collected request responses, "Internal modifier" and "Supportive moves " were the most frequently used strategies among under 26 years subjects respectively. The same table shows that out of 71 collected request responses "Internal modifier" and "Alerters" was the most popular employed strategies among above 26 years subjects respectively.

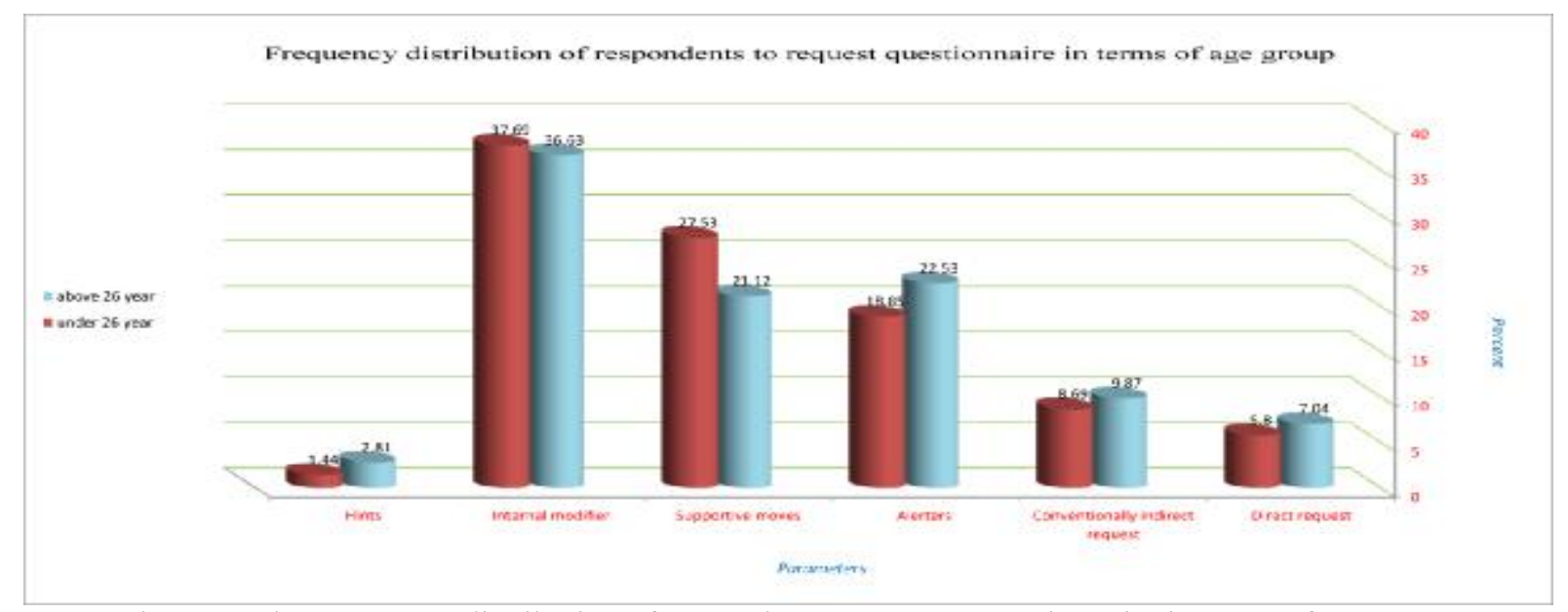

Figure 2. The Frequency distribution of respondents to request questionnaire in terms of age group

3.2.3 The Frequency distribution of respondents to request questionnaire in terms of educational degree Table 6. Frequency distribution of respondents to request questionnaire in terms of educational degree

\begin{tabular}{cllll}
\hline Educational degree & Frequency & Percent & Cumulative Percent \\
\hline B.A & Direct request & 2 & 5.13 & 5.13 \\
& Conventionally indirect request & 3 & 7.70 & 12.83 \\
& Alerters & 7 & 17.95 & 30.78 \\
& Supportive moves & 11 & 28.20 & 58.98 \\
& Internal modifier & 15 & 38.46 & 97.44 \\
& Hints & 1 & 2.56 & 100.0 \\
M.A & Total & 39 & 100.0 & \\
& Direct request & 1 & 1.85 & 1.85 \\
& Conventionally indirect request & 3 & 5.55 & 7.4 \\
& Alerters & 14 & 25.93 & 33.33 \\
& Supportive moves & 12 & 22.22 & 55.55 \\
& Internal modifier & 23 & 42.60 & 98.15 \\
& Hints & 1 & 1.85 & 100.0 \\
& Total & 54 & 100.0 & \\
& Direct request & 1 & 2.13 & 2.13 \\
& Conventionally indirect request & 1 & 2.13 & 4.26 \\
& Alerters & 11 & 23.40 & 27.66 \\
& Supportive moves & 15 & 31.91 & 59.57 \\
& Internal modifier & 18 & 38.30 & 97.87 \\
& Hints & 1 & 2.13 & 100.0 \\
\hline
\end{tabular}

As this table reveals, out of the 39 collected request responses, "Internal modifier" and out of the 54 collected request response, "Internal modifier" was the most frequently used strategies among B.A and M.A subjects respectively. The same table shows that out of 47 collected request responses "Internal modifier" and "Supportive moves" was the most popular employed strategies among PHD subjects respectively.

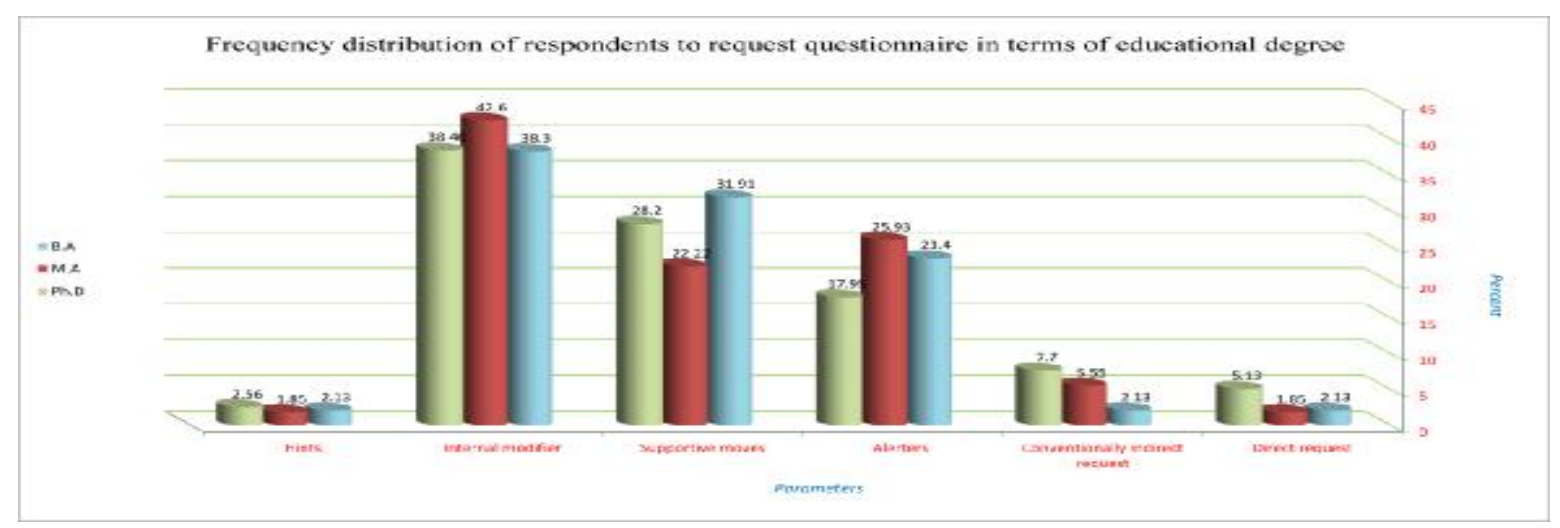

Figure 3. Frequency distribution of respondents to request questionnaire in terms of educational degree 


\section{Discussion and Conclusions}

The results indicated that, Persian and Kurdish speakers demanded through using the same strategies supportive moves belong to the request speech act. In addition, speakers above and fewer than 26 years old demanded through using the same strategies internal modifier and all three educational degree such as BA,MA,PHD demanded through using internal modifier more than other request speech act strategies. Therefore, it seems that in Persian and Kurdish, requests are as formulaic as in other investigated languages, yet preferences for using request parameters seem to be culturespecific. The results, on the other hand, confirm previous findings suggesting the universality of request parameters and on the other hand, it supports the scholars who emphasize the culture-specific aspect of language. According to the fames theory by Brown and Levinsons Politeness Model regards apologies as negative politeness strategies in that they convey respect, difference, and distance rather than friendliness and involvement. Negative politeness is avoidancebased, on-record strategy of self-effacement and restraint. Evidence of positive politeness can be seen in request and apology (e.g., responsibility, tendency), and individual linguistic and extra linguistic elements. Request is face respectability for the speaker and face usefulness for the addressee. In contrast with negative politeness, positive politeness is an Involvement-based approach made by the speaker to ratify, understand, approve of, and admire the positive image of the addressee (Brown and Levinson, 1987).

In the present study, we have tried to design multiple choices of both request and questionnaire in accordance to the relevant parameters in order to apply the concepts of negative and positive politeness in appropriate locations. Therefore, respondents answered to questions based on visualize location and their probable response. By attention to another main theory by Austin (1962) who defines the performance of uttering words with a consequential purpose as "the performance of a locutionary act, and the study of utterances thus far and in these respects the study of locutions or of the full units of speech" (p. 69). These units of speech are not tokens of the symbol or word or sentence but rather units of linguistic communication and it is the production of the token in the performance of the speech act that constitutes the basic unit of linguistic communication" (Searle, 1965, p.136). These functional units of communication have prepositional or locutionary meaning (the literal meaning of the utterance), illocutionary meaning (the social function of the utterance), and perlocutionary force (the effect produced by the utterance in a given context) (Cohen, 1996, p. 384).) Furthermore, we have tried to design multiple choices of both request questionnaires in accordance to classification of functional units of communication in above mentioned grouping. It means that the type of parameters once is refers to locutionary meaning (the literal meaning of the utterance) and in elsewhere, models are appropriate to illocutionary meaning (the social function of the utterance), and finally some others choices means perlocutionary force (the effect produced by the utterance in a given context). Therefore, Researcher is considered the responses of participants in which know according to different variables who have choose locutionary, illocutionary and perlocutionary meaning. In the other word, researcher has tried to find the answer of whatis the most frequent strategy among variables in each question? Regarding to the conclusion of the research and according to the findings and results of the study, we can see in order Ilami- Kurdish and Persian speakers in request speech act have had maximum use of the same strategy such supportive moves in which frequency percent 38.57 in Kurdish people and 35.71 in Persian. According our searches there was no related study. we can see in order three educational level speakers in request speech act have had maximum use of the same strategy such Internal modifiers in which frequency percent 38.46was in BA and 42.60 in MA and 38.30 in PHD.

\section{References}

Afghary, A. (2007). Pragmatics and speech act theory Research Week proceedings, Isfahan University, Isfahan.

Austin, J.L. (1962). How to Do Things with Words. Oxford University Press Oxford.

Austin, J.L. (1975). How to do things with words. J.O. Urmson\& M. Sbisa, edsCambridge, MA: Harvard UP.

Blum-Kulka, S., \& House, J. (1989). Cross-cultural pragmatics: Requests and apologies. Norwood, N.J. Ablex.

Blum-Kulka, Sh., \& Olshtain, E. (1984). Request and apologies: a cross-cultural study of speech act realization patterns (CCSARP).

Brown, P., \& Levinson, S. (1978). Universals in language usage: Politeness phenomena. In E. N. Goody (Ed.), Questions and politeness: Strategies in social interactions (pp. 56-289). Cambridge: Cambridge University Press.

Brown, P., and Levinson,S. (1987). Politeness: Some language universals in language use. Cambridge: Cambridge University Press.

Blum-Kulka, S. (1984). Interpreting and performing speech acts in a second language: a cross-cultural study of Hebrew and English' in N. Wolfson and J. Elliot (eds.). TESOL and Sociolinguistic Research. Rowley, MA: Newbury House. Campbell, S. (1994). Being Dismissed: The Politics of Emotional Expression. Hypatia, 46-65.

Chomsky, N. (1994). Grammatical competence theory. London: Routledge.

Cohen, A. (1996). Speech Acts, in S.L. McKay, \& N.H. Hornberger (Eds.), Sociolinguistics and language.

Eemeren, F., \& Grootendorst, R. (1984). Speech Acts in Argumentative Discourse. Dordrecht, Holland: Foris.

Thomas, J. (1983). Cross-cultural, pragmatic failure'. AppliedLinguistics4/2:91-Widdowson,H.1978. Teaching Language as Communication. London: Oxford, University Press. 
Searle, J. (1979). Expression and Meaning. Cambridge: Cambridge University Press.

Fraser, B. (1975). Hedged performatives' in P. Coleand S.L. Morgan. Syntaxand semantic, Vol.3.NewYork: Academic Press.

Gilbert, M. A. (1995). The Delimitation of Argument. Inquiry, 15(1), 63-75.

Gilbert, Michael A. (1997). Coalescent Argumentation. New Jersey: Lawrence Erlbaum Associates.

Gilbert, Michael A. (1997). Prolegomenon to a Pragmatics of Emotion "Proceedings of the Ontario Society for the Study of Argumentation. St. Catherine's, ON: Brock University.

Grice, H.P. (1975). Logic and conversation. In A. Jaworski, \& N. Coupland (Eds.), "The discourse reader". New York: Routledge.

Gumperz, J. (1982). Discourse strategies. Cambridge: Cambridge University Press.

Gumperz, J. (1990). The conversational analysis of interethnic communication.In R. C. Scarcella, E. S. Andersen, and S. D. Krashen (Eds.), Developing communicative competence in a second language: Series on issues in second language research (pp. 223-238). Boston: Heinle \& Heinle Publishers.

Fillmore, C. (1971). Towards a theory of deixis. ThePCCLLUPapers3/4:219-41 (Department of Linguistics, University of Hawaii).

FilLnore, C. (1975). Santa Cruz Lecture son Deixis. Indian University Linguistics Club (mimeo).

House, J. (1982). Conversational strategiesin Germanand English dialogues' in G.Nickeland D.Nehls (eds.). Error Analysis. Constructive Linguistics and Second Language Learning (Special Issue of IRAL).Heidelberg: Julius Groos

Olshtain, E., and Blum-Kulka. S. (1983). Degree of Approximation'. Paper presented At Language In Putin Second Language Acquisition Conference, Ann Arbor Michigan.

Lakoff, R. (1973).The logic of politeness: or minding yourp'sandq's. Proceedings Of the Ninth Regional Meeting of the Chicago Linguistic Society.

Labov, W., and Fanshel, D. (1977).TherapeuticDiscourse. NewYork: Academic Press.

Kasper, G. (1981). Pragmatische aspect in there Interimsprache. Tubingen: Gunther Narr.

Sillince, J. A. A. (1994). There is more to Emotion than Goal Attainment. Genetic, Social and General Psychology Monographs.

Willard, C.A. (1989). A Theory of Argumentation. Tuscaloosa: U. Alabama Press. 